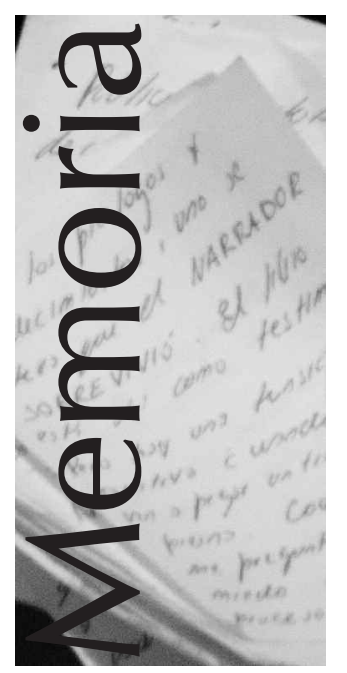

\title{
La capacitación, la enseñanza y la investigación para una política de reconstrucción nacional en el área de la salud
}

\section{Training, teaching and research for a policy of national reconstruction in the health field}

Testa, Mario ${ }^{1}$

RESUMEN Este texto reproduce el discurso pronunciado por el Dr. Mario Testa, el 28 de junio de 1973, en el aula magna de la Facultad de Medicina de la Universidad de Buenos Aires. Las líneas introductorias que lo anteceden, escritas por el propio autor, contextualizan no solo el momento histórico de aquella universidad, a pocos días de la asunción de Rodolfo Puiggrós como rector interventor, sino el sentido del proyecto de renovación pedagógica que proponía una redefinición de la relación entre universidad y sociedad y que dio origen a proyectos como el Instituto de Medicina del Trabajo, el Instituto de la Madre y el Niño y el Instituto de Patología Regional, en la Facultad de Medicina; el Centro de Producción de Medicamentos de Base en la Facultad de Farmacia y Bioquímica; el de Erradicación de Villas de Emergencia en la Facultad de Arquitectura, entre tantos otros. Volver a publicar aquellas palabras pronunciadas hace casi 40 años es poner en discusión el significado y el sentido de la formación de profesionales de la salud financiada con fondos públicos. PALABRAS CLAVE Facultades de Medicina; Educación Médica; Formación de Recursos Humanos; Corporaciones Profesionales; Argentina.

ABSTRACT This text reproduces a speech given by Dr. Mario Testa on June 28, 1973 in the main hall of the Faculty of Medicine of the Universidad de Buenos Aires. The words of introduction preceding the text, written by Testa himself, provide the context of not only the historical moment the university was experiencing, just days after Rodolfo Puiggrós took office as the rector within the university's political overhaul, but also the meaning given to the project of pedagogical renovation. This project proposed redefining the relationship between the university and society, originating such projects such as the Instituto de Medicina del Trabajo (Institute of Occupational Medicine), the Instituto de la Madre y el Niño (Mother and Child Institute) and the Instituto de Patología Regional (Regional Pathology Institute) in the Faculty of Medicine; the Centro de Producción de Medicamentos de Base (the Center for Basic Drug Production) in the Faculty of Pharmacy and Biochemistry; and the Centro de Erradicación de Villas de Emergencia (Center for the Eradication of Shantytowns) in the Faculty of Architecture, among many others. Republishing these words, spoken almost 40 years ago, is a way of continuing to put into discussion the type of education and training health professionals receive with public funds.

KEY WORDS Schools, Medical; Education, Medical; Human Resources Formation; Professional Corporations; Argentina.

${ }^{1}$ Médico. Doctor Honoris Causa, Universidad Federal de Bahía, Brasil. Profesor, Universidad Nacional de Lanús, Argentina. asiaymario@gmail.com 


\section{ACERCA DEL DISCURSO}

Estas líneas introductorias intentan aclarar las circunstancias en que las palabras del texto que sigue fueron pronunciadas por mí en el aula magna de la Facultad de Medicina de la Universidad de Buenos Aires (UBA).

Era el año 1973 y yo desempeñaba el cargo de Delegado del Interventor de la UBA, en manos de Rodolfo Puiggrós. El equipo que me acompañaba estaba constituido por unas 25 personas con un compromiso total en la tarea que emprendimos.

Héctor Cámpora era presidente de la República y se vivía en un clima político de una intensidad tal que sus huellas siguen hasta el día de

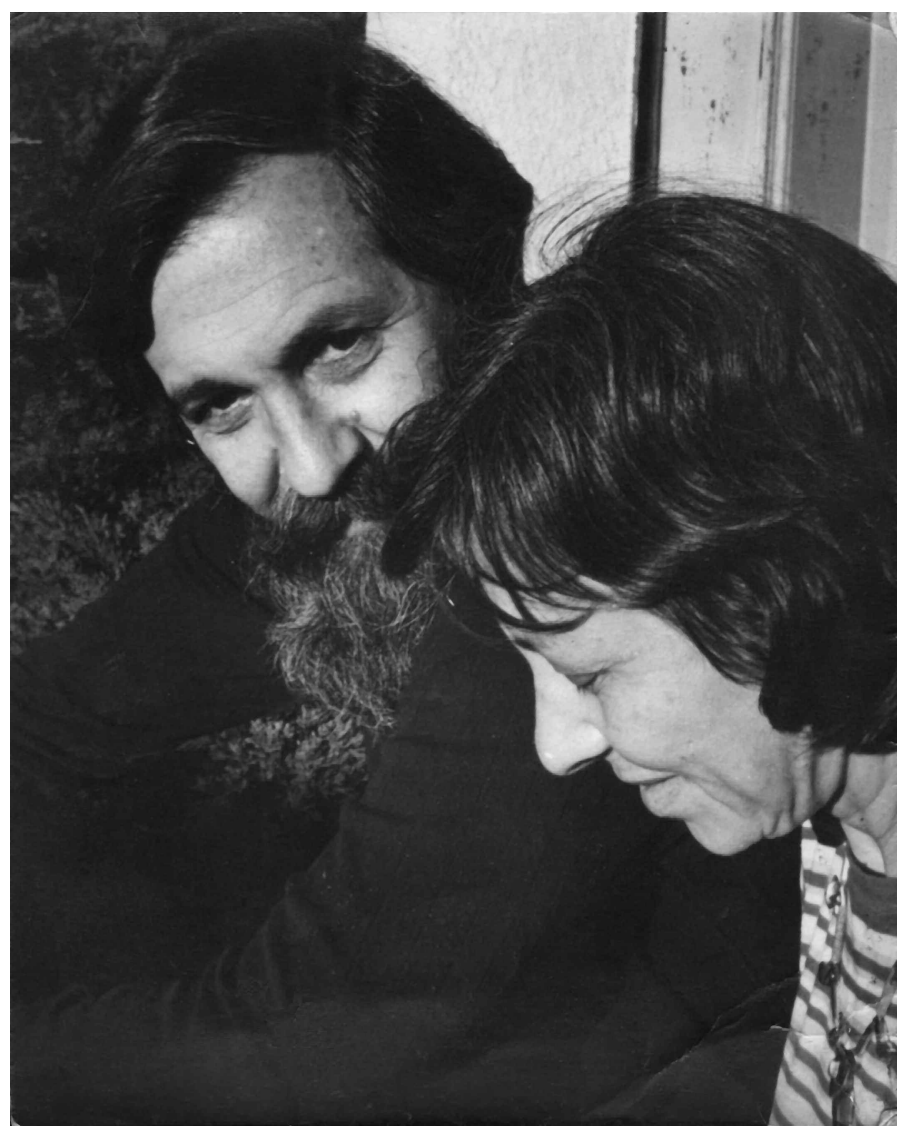

Mario Testa y Asia Selvin. 1973 hoy, dando nombre a una forma de la política que hacía presumir grandes transformaciones: el setentismo. Un cartel proclamaba decididamente: Cámpora gobierna con el pueblo, Perón conduce la liberación. La historia que siguió dirá otra cosa.

La Universidad no escapaba a ese clima y nuestra consigna era que teníamos que trabajar para transformar la universidad tradicional en una universidad "necesaria". Para intentar hacerlo introdujimos modificaciones curriculares que iban en la dirección que se refleja en el texto que sigue. Y también comportamientos que estimulaban el trabajo en equipo, tantas veces declamado y tan poco (o nada) incorporado en las prácticas asistenciales.

Así fue, por ejemplo, que planteamos la posibilidad de exámenes no individuales sino colectivos en pequeños grupos, lo que fue duramente resistido (como habíamos supuesto que ocurriría) por docentes y familiares de alumnos, y no tanto por los mismos alumnos. La cuestión sobrepasó el ámbito universitario y fuimos convocados por un grupo de senadores nacionales (algunos de ellos médicos) para que diéramos explicaciones de esa extraña propuesta.

La reunión se realizó en la Escuela de Salud Pública y ante nuestras explicaciones de las razones que nos Ilevaron a tomar esa decisión se calmaron algo los ánimos ofendidos.

Pero el propósito de estas líneas va más allá de lo dicho hasta aquí. Porque nosotros, los que teníamos la responsabilidad de la conducción de la Facultad, también éramos un colectivo y nos comportábamos como tal, solo que asumiendo cada quien el rol que convenía en cada momento según las circunstancias que enfrentábamos.

Por eso, el texto que sigue y lleva mi firma (y que seguiría firmando hoy como hace casi cuarenta años) no es de mi exclusiva autoría sino del equipo (que hoy llamaría sujeto colectivo) que conformábamos y que promovíamos en nuestros estudiantes. Esta confesión no era conveniente ni prudente ni estratégica hacerla entonces, sería injusto no hacerla hoy. 


\section{DISCURSO PRONUNCIADO POR EL DELEGADO INTERVENTOR EN LA FACULTAD DE MEDICINA DR. MARIO J. TESTA, EL 28 DE JUNIO DE 1973}

Compañeras y compañeros:

El gobierno nacional popular que preside el compañero Cámpora, y que conduce el Teniente General Perón, ha inaugurado un período del que surgirán profundas transformaciones en la vida del país. Estas transformaciones comienzan con la enorme tarea de la reconstrucción nacional, para tratar de recuperarnos, en el menor tiempo posible, del deterioro producido por 18 largos años de desgobierno, agravados a partir del 66 en la etapa que podríamos Ilamar de catástrofe nacional.

Todos conocemos los hechos: la represión sangrienta es necesaria cuando la opresión económica lleva la participación del salario obrero desde el $55 \%$ del ingreso nacional a muchos menos del $40 \%$. La entrega del patrimonio nacional requiere cómplices bien pagados en el país: en las empresas para manejar desde aquí el negocio de enviar al exterior lo que se robó a los trabajadores, en los sindicatos para acallar la protesta, en la policía para solucionar en definitiva el problema.

¿Qué tiene esto que ver con la Facultad de Medicina de la Universidad de Buenos Aires? Tiene que ver porque un solo dato oprobioso sintetiza como ninguno esta conocida historia. Más de sesenta de cada 1.000 niños que nacen vivos se mueren en el primer año de su existencia. Esto ha ido en aumento en los últimos años. Los niños que mueren son, en su gran mayoría, hijos de esos mismos obreros que han visto impotentes deteriorarse su salario. Es decir, existe una obvia relación entre ambos hechos que no puede menos que hacernos reflexionar sobre nuestro propio quehacer. ¿Qué estamos enseñando?, ¿como los estamos haciendo?, ¿a quiénes y para qué?

El gobierno nacional y popular ha expresado con convicción y firmeza su posición clara frente a los problemas del país. En lo que respecta a salud, las más altas autoridades se han expresado en términos coincidentes y decisivos. Dijo el compañero Cámpora:
Nuestro gobierno propugnará el establecimiento de un sistema único nacional de salud para el que no deben existir fronteras provinciales o comunales, ni sindicales. Será el responsable de asegurar el flujo ascendente de la programación, canalizando las expectativas y necesidades populares, y tendrá como fin promover la integración entre acciones de los equipos técnicos y las necesidades de la población, y a su vez promoverá la toma de conciencia de otras necesidades en salud.

Será asimismo propósito esencial de nuestro gobierno justicialista, fomentar la industria nacional de medicamentos y productos biológicos regulando su importación y eliminando la libre comercialización de dicha industria, para terminar así con la especulación y el lucro.

En otro párrafo de su discurso en el Congreso, el compañero agregó precisión a la propuesta:

\footnotetext{
...las prestaciones y servicios deben darse por la simple condición humana de quién los recibe, no admitiéndose diferencias. Para ello tales servicios serán, en principio, gratuitos y se eliminarán las barreras culturales, geográficas y económicas que hoy registran privilegios y restringen el acceso a los servicios de salud.

Además, no debe existir libre empresa en cuanto a quienes intervienen en problemas de la asistencia médica, ya que esta favorece una estéril competencia entre entidades y sistemas, incrementa considerablemente los costos, crea desigualdades en la atención de los enfermos, hace un uso indiscriminado de la tecnología y distribuye inadecuadamente los recursos, ejerce una práctica individualista y deshonesta de la medicina $y$ un superfluo consumo de medicamentos y drogas favoreciendo las formas sofisticadas y triviales de la atención médica.
}

Estas proposiciones han sido corroboradas totalmente por el compañero subsecretario de Salud Pública, con el agregado de algunas precisiones en cuanto a su forma de financiamiento: "desalentaremos -dijo- toda solución que parta de un nuevo gravamen al salario de los trabajadores y del pago directo de los servicios médicos", destacando asimismo que la reconstrucción se hará tomando como base el hospital en torno al cual 
se reorganizará la red de servicios. Anunció además la creación de una carrera sanitaria nacional que incluirá todo el equipo de salud.

Para entender lo que significan las propuestas enunciadas es necesario analizarlas a la luz de la situación actual del sector salud en nuestro país.

La característica más importante en el momento en que el gobierno es asumido por el compañero Cámpora, y que me interesa destacar aquí, es la pérdida de la conducción nacional en el sector salud. Por otra parte, el caos organizativo, la competencia desenfrenada, la alienación de los profesionales de salud, la inestabilidad e inseguridad y la ausencia total de solidaridad entre profesionales y pueblo y de participación popular o profesional en cuanto a la situación de salud condicionan lo que puede considerarse una situación alienada del sector.

Hasta el 25 de Mayo, el Estado tiende a desentenderse de la financiación de la salud. Esto, agravado por el deterioro del salario, la falta de vivienda, la ausencia de medicina preventiva y la detención del crecimiento de la infraestructura hospitalaria pública, deja especialmente desprotegidos a los grupos de población que más necesitan del auxilio del Estado. Por si fuera poco, la reciente Ley 19.337 de descentralización hospitalaria esconde detrás de la aparente buena intención de agilizar su administración el avieso propósito de descargar sobre la comunidad su sostenimiento.

De esta manera, también en el sector público la salud queda librada al juego de la oferta y la demanda, y la enfermedad se convierte en objeto de lucro. El criterio de beneficio priva sobre el de servicio.

Las reglas del juego son: asistencia de la enfermedad = lucro. Es natural que proliferen las instituciones "asistenciales" y que predominen en detrimento de las preventivas, ya que lograr una comunidad sana conspire contra las ganancias.

El negocio se orienta hacia los sectores de medianos y altos ingresos, con sistemas de prepago, coseguros, etc., y a un determinado grupo de enfermos: el agudo, el quirúrgico, la parturienta, que reditúa grandes ganancias. Por excepción alguien se ocupa del crónico, que por estar crónicamente enfermo se empobrece, y con el pobre nadie hace negocio, así es más barato morirse.
El sistema se perfecciona y trata de maximizar las ganancias. Aparecen así las instancias organizativas superiores que significan un importante cambio de carácter de los tradicionales y lujosos sanatorios: los monopolios de la salud, que procurarán de ahora en más regentear el negocio de la enfermedad.

Apelan a la propaganda masiva para monopolizar sectores muy redituables y exclusivos de la medicina altamente especializada. Con "servicios vidriera" venden una imagen de seriedad y capacidad "científica" que, en el fondo, se rige por la ley de atender más con cada vez menos.

Esta transformación del subsector privado se produce a pesar del encarecimiento progresivo de la tecnología médica, porque también han cambiado sus clientes. La tabla de salvación proviene del crecimiento de los fondos de las obras sociales y sindicales y la posibilidad de firmar cuantiosos contratos con ese grupo social.

La mutual y la obra social nacen como expresión de solidaridad y como logros reivindicativos de los sectores involucrados. Pero se advierte la aparición de dos fenómenos que progresivamente irán cambiando su carácter: la atención médica del sector productivo es objeto de creciente interés por los monopolios de la salud, que ven en esta área una fuente de financiamiento para la expansión de sus propias empresas de salud. Esto se explica porque la capacidad instalada propia de las obras sociales es apenas del $5 \%$ sobre el total del país y está concentrada en Buenos Aires y otras pocas ciudades industriales (Rosario, Córdoba). De esta manera, el grueso del aporte de los asalariados debe canalizarse hacia instituciones privadas, por contratación directa o a través de colegios o federaciones médicas, que operan como mecanismos de intermediación financiera y de gestión empresaria. Esta situación es aprovechada, en muchos casos, por grupos identificables, que utilizan políticamente el manejo de la salud de los afiliados y las sumas de dinero en juego, que son muy considerables, para perpetuarse en la conducción gremial u obtener beneficios personales, en perjuicio del conjunto de los trabajadores.

Esto nos introduce en la consideración de un nuevo aspecto pocas veces mencionado: la prevención de la salud del trabajador. De nada valen planes sanitarios si el eje no pasa por prevenir la 
enfermedad. En el caso del trabajador, de nada sirven las obras sociales si las máquinas y las condiciones de trabajo y de vida lo siguen enfermando. Y hasta ahora la prevención en el área laboral no solo ha sido cubierta insuficientemente sino que se ha mantenido en manos oligárquicas. Porque hasta que ese importantísimo sector del área de salud no pase a manos realmente populares, nada de lo más querido del régimen se habrá afectado.

Los médicos participan de manera desigual en todo este panorama. En primer lugar, la gran masa médica deambula explotada en ese laberinto entretejido por los monopolios de salud. Sometidos a regímenes de "eficiencia" deben atender cada vez más pacientes con cada vez menos y en el menor tiempo posible; vive sojuzgada en lo económico, desalentada en lo científico, sin ningún tipo de resguardo social, ni aun cuando se enferma. Una verdadera situación de explotación de la cual, en general, no solo no son conscientes, sino que hasta llegan a ser cómplices del mismo sistema explotador que los instrumenta.

Las pequeñas clínicas y sanatorios son un intento organizativo de los más vivos e inescrupulosos, pues ofrecen una asistencia médica que saben muy bien que no pueden dar en el nivel que deberían.

Por último, los verdaderos empresarios de la salud, que lucran con la enfermedad del pueblo y explotan a sus propios colegas.

Es evidente que el grueso de la masa médica que percibe un honorario global en las clínicas y no está rentada en los hospitales (concurrentes), y aun muchos de los rentados y asalariados tienen intereses contrapuestos a los monopolizadores de la salud. No obstante ello, esta masa médica se pierde en luchas menores o secundarias, inspirados por sus propios explotadores, terminando por expresarse en contra de sus propios intereses. No advierten que su propia pauperización es lo que permite el enriquecimiento de sus patrones y el engrandecimiento de las "empresas de salud".
Los empresarios y profesionales interesados en el comercio de la salud siguen alimentando en sus colegas la tramposa esperanza del retorno a la medicina liberal, del floreciente consultorio particular, de los privilegios médicos, de la promoción individualista a través de la competencia "científica", etc. El quehacer gremial, a contrapelo de la realidad de las bases y de la historia, no busca esclarecer las verdaderas causas de la situación. Ignora el hecho fundamental de una gran masa médica que no tiene privilegios que defender, que trabaja todo el día en pésimas condiciones científicas y laborales, a los que cada día resulta más claro que no les queda otra esperanza que llegar a fin de mes con los tres trabajos. A este conjunto de médicos explotados es que se les ofrecen también dos caminos: seguir dejando que se los explote o asumirse como trabajadores

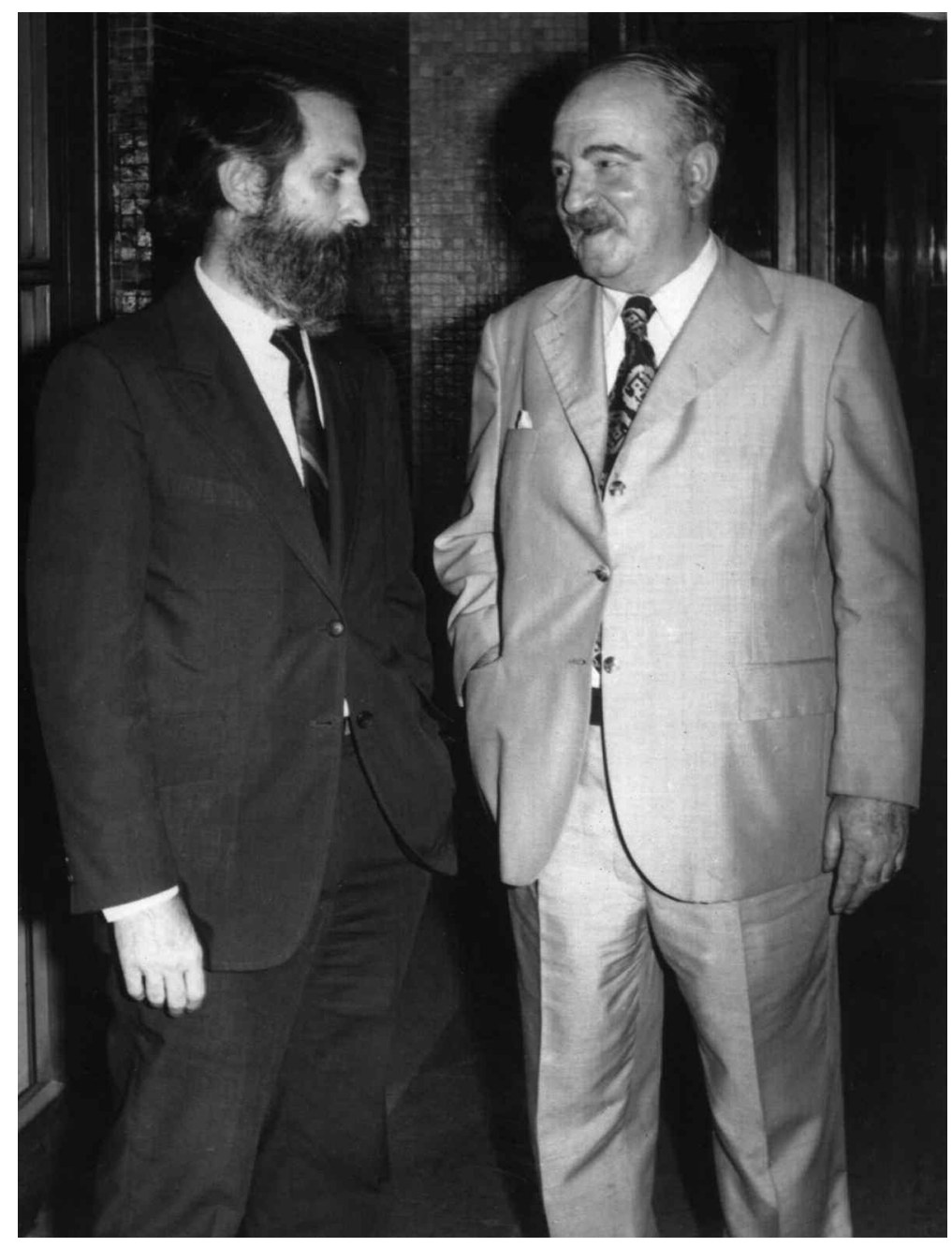

De izquierda a derecha: Mario Testa y Rodolfo Puiggrós. 1973 
de la salud. De nuevo opresión o liberación. Marginarse del pueblo para conservar las migajas de privilegio que hoy les conceden sus patrones, o integrarse con el pueblo en el proceso de liberación social y nacional.

El equipo de salud está formado por una gama extensa de profesionales, técnicos y de otro personal. La situación de todos ellos no es homogénea. Algunos viven aproximadamente la situación idílica que era privilegio de los médicos durante la primera mitad de este siglo, otros de los cuales son paradigma el personal de enfermería, sufren una explotación que no tiene nada que envidiar a la que padecen los médicos proletarizados del sistema. Turnos excesivos con horarios que se prolongan a veces más allá de lo tolerable, salarios insuficientes que obligan a la complementación con la "changa" o el doble empleo, nivel de capacitación inadecuado y las condiciones en que se desarrolla el trabajo hospitalario, hacen que el hilo se corte por lo más delgado y el personal vuelque su frustración sobre quienes no pueden hacer oír su voz de protesta: los pacientes.

La formación de personal no tiene un programa o una política que lo oriente a cubrir necesidades obvias de la población, porque los centros de decisión de políticas de la salud y de personal no existen o no se conocen entre sí. Esto ocasiona plétoras o insuficiencias parciales, lo cual conduce a dos situaciones insatisfactorias: competencia desatada por los pocos cargos existentes o distorsiones en la composición del equipo de salud.

Conjuntamente se observa una distribución geográfica de personal de salud y de población que lleva a zonas con un médico cada doscientos habitantes y otras con relación de uno a cinco mil, clara consecuencia de que la producción de servicios no está programada en función de las necesidades de la población.

Por otra parte, en la composición del equipo de salud se dispone de una enfermera por médico, o 0,7 enfermera capacitada formalmente por médico, o existen carencias notorias en especialidades críticas como geriatría, anatomopatología, epidemiología y otras. ¿Qué sacrificios estamos haciendo nosotros para poder pedir que se estudie enfermería, sabiendo que es una profesión exigente, con salarios miserables y sin reconocimiento social? En estas condiciones, estudiar enfermería es un acto de heroísmo, y estudiar enfermería en la Universidad un acto de audacia, salvo que se emigre a un país desarrollado. Mi homenaje a los audaces y a los héroes. De nuevo obtenemos el mismo resultado: el resentimiento de la salud del pueblo.

\section{Los medicamentos}

La industria montada en torno a los medicamentos muestra con toda crudeza lo que la rapacidad empresarial y la penetración imperialista han logrado en nuestro país. La situación debe ser analizada a nivel del mercado, los precios y la dependencia.

El mercado de medicamentos es de un tipo muy especial. Se trata de un consumo que, exceptuado el caso de los remedios autorrecetados, no cae bajo la elección del consumidor directo, sino que es manejado por el médico que extiende la receta. Este crea una relación muy particular entre médicos y laboratorios farmacéuticos, ya que estos destinan un volumen importante de recursos a una propaganda sumamente especializada que se vuelca sobre los médicos. Esa propaganda asume en ciertos casos características de "soborno".

La literatura que los laboratorios distribuyen es, por otra parte, casi la única fuente de información donde los médicos pueden conocer las últimas novedades acerca de actuación de drogas y medicamentos; de más está decir que esa información no siempre es todo lo exacta que debiera.

El precio de los medicamentos es de tal magnitud que hace que el gasto en los mismos esté cercano al $40 \%$ del gasto total en salud por parte de la población. Este precio se fija en condiciones oligopólicas en el mejor de los casos, pero por lo mismo que se ha señalado al caracterizar el mercado: no existe una competencia en base a calidades o precios de productos similares porque el médico es el que decide. De ahí que la incidencia de la propaganda en el precio sea tan considerable, lo cual evidencia al considerar los diversos ítems que la componen: regalos, literatura lujosa con impresiones de calidad inmejorable, marcación "hombre a hombre", distribución de muestras gratis, además de la propaganda dirigida al grueso de la 
población. Se calcula que no menos de un $22 \%$ de la facturación de los laboratorios importantes corresponde a este concepto.

Otro elemento que encarece artificialmente el medicamento es la diversificación de productos que reproducen otros similares ya existentes en el mercado. El agregado de cantidades infinitesimales de vitaminas, antiespasmódicos, alcalinizantes, acidificantes, o cualquier otra cosa a un producto ya existente permite cambiar su nombre y, lo que es más interesante, duplicar su precio. Esto no encontró, por lo general, ninguna oposición en los medios oficiales que deben autorizar la aparición de nuevos medicamentos.

Como es natural, la intermediación para que el producto Ilegue al consumidor recarga lo que ya de partida es un exceso. Se estima que, en promedio, las droguerías agregan un $22 \%$ y las farmacias un $12 \%$ al precio con que les llega el producto. Esto admite algunas variantes, como por ejemplo la sensible disminución que tienen las obras sociales, que solo incrementan un $9 \%$ sobre el precio de fábrica.

Hasta aquí se han considerado elementos que, si bien abultan injustamente los precios de los medicamentos, pueden ser considerados "normales" en una industria que se rige por las duras leyes del capitalismo. Pero además existe lo que no puede ser considerado de otra manera que como un robo. Este asume formas diversas, de las cuales son conocidas: la sobrefacturación de insumos importados que, para algunos laboratorios, son la mayoría, aun cuando los mismos se fabriquen en el país a precios y con calidad competitivos; el envío irregular de ganancias al exterior, disimuladas en alguno de los numerosos rubros de contabilidad en los que esas empresas son especialistas, son formas que asumen esa expoliación.

Por último, la dependencia que significa la industria de medicamentos por las empresas extranjeras de los países imperialistas, se expresa en forma directa a través del envío de divisas en conceptos de regalías técnicas, muchas veces innecesarias porque existen tecnologías alternativas nacionales o adquiribles a menor costo, pero que no se pueden utilizar porque el contrato que permite usar la "marca" prestigiosa incluye la obligación del uso de esa técnica o, más fácil aún, porque la compañía nacional es una subsidiaria de la matriz cuyos intereses defiende.
Todo es coherente, la situación políticosocial y económica del país con su dependencia ante el imperialismo y el dominio que ejerce su oligarquía. La política estatal de salud con el papel que juegan las obras sociales y el subsector privado. Los empresarios de los monopolios de salud con la medicina del trabajo y todo ello con que las ganancias vayan a parar adonde van siempre: las arcas de la oligarquía y el imperialismo. El ciclo se ha cerrado, la salud del pueblo espera.

A esta situación se llega a través de una historia que es, en parte, condicionada por una política. Veamos las sucesivas fases de ese proceso.

Antes de Perón, se pueden distinguir dos subperíodos desde comienzo de siglo: uno que va aproximadamente hasta la crisis de 1930 y otro que abarca desde entonces hasta 1945. Ambos se caracterizan por una misma apreciación liberal del problema salud, pese a los intentos o anuncios de algunos protosanitaristas $y$ administradores.

En el comienzo existe un doble sistema de atención médica, sin puntos de contactos. Por un lado, un subsector privado para pacientes ricos y para una clase media relativamente acomodada, que puede acceder al mismo porque la medicina es relativamente "barata", en el sentido de que no utiliza equipos o instrumental complicado; los consultorios privados y los sanatorios forman una eficiente red asistencial para ese grupo social. Por otra parte existe el hospital público, generalmente provincial o municipal, destinado a realizar obra de caridad (la institución más importante que los nuclea en determinado momento es la "sociedad de beneficencia") y frecuentado en consecuencia por los pobres, entre los que se incluye a casi toda la clase obrera.

La mejor medicina es la que se realiza en el subsector privado, regido para su funcionamiento por un mecanismo estricto de mercado, en el que el "cliente" se hace cargo del costo total de su atención y en el que el médico tiene asegurado un estatus social importante y un ingreso relativamente elevado. El hospital público o semipúblico es, en general, una institución pequeña y aislada sin obligación de cubrir con servicios a toda la población, pero que le sirve al médico como lugar de entrenamiento y aprendizaje. Esto último es lo que, ya en el transcurso de 
este subperíodo, va a hacer del hospital público un centro de importancia científica.

Los adelantos que se producen en materia de salud pública dependen más de obras generales de infraestructura (por ejemplo, agua corriente) que de las aisladas acciones de prevención (vacunaciones).

Lo más destacado de esta etapa en lo que respecta a atención médica es que comienzan a afirmarse tres características importantes: hay una medicina para ricos y otra para pobres, una para las grandes ciudades y ninguna para el campo, se perfila un creciente interés para restablecer rápidamente la salud del sector productivo: los trabajadores.

En la segunda parte de este período se perciben ya cambios importantes. La medicina se hace cada vez más compleja y, en consecuencia, cara. Los sanatorios privados dejan de ser accesibles para una buena parte de la clase media, sobre todo si se toman en cuenta las circunstancias de la crisis de 1930 y sus posteriores efectos. El hospital público se afirma como centro científico y aumenta su nivel de complejidad, incorporando equipos e instrumental que, por su dimensión o su costo, resultan inaccesibles para las instalaciones privadas. De esta manera, lo sanatorial deja de ser lo mejor pero sigue siendo lo más caro. Como el hospital público es gratuito se entiende que capte buena parte de la clientela antes privada. Sin embargo, como se mantiene el sistema de consultorios privados, aparece una forma de conexión entre ambos subsectores: la atención en la consulta del médico privado, al mismo tiempo que el uso del hospital público por el mismo paciente para los exámenes auxiliares, ciertas formas de tratamiento y aun la internación, lo cual responde a la necesidad de crear una válvula de escape que sirva primordialmente al interés de la medicina liberal.

Aparecen los primeros gérmenes de un mecanismo parcial de solidaridad en grupos relativamente cerrados: las mutuales sindicales en la clase obrera y las instituciones asistenciales de colectividades extranjeras. Ambas intentan conservar algunas características del subsector privado, pero desplazando el pago del servicio del cliente al grupo entero.

Otra característica que se evidencia en este lapso es la de la ampliación del campo que abarca la salud pública a través de programas dirigidos centralmente y que se ocupan de inmunizaciones masivas de la población y de atención de problemas de saneamiento ambiental. Esto tiene manifestaciones institucionales, por ejemplo, la consolidación del Instituto Malbrán como uno de los centros de preparación de biológicos y vacunas, y laboratorio de referencia de importancia mundial. Alvarado comienza a instrumentar su lucha antipalúdica.

Con Perón, el Estado toma firmemente la conducción del proceso. Esta etapa se caracteriza por una comprensión diferente de los problemas de salud. Esto es lógico por cuanto el marco político se modifica y el pueblo es actor del proceso. La salud se interpreta como un derecho al cual debe tener acceso no solo el enfermo sino también el sano.

Las transformaciones son profundas. El Departamento de Higiene se convierte en el Ministerio de Salud Pública. Carrillo establece por primera vez en el país un plan coherente que abarca todos los aspectos del problema salud y toda la población. La noción de cobertura se manifiesta a través del crecimiento del número de camas del subsector público, que se duplican. Este incremento se hace de tal manera que se facilita la accesibilidad de la población rural a los servicios, a través de una mejor distribución de estos en todo el territorio nacional. El hospital adquiere, además, una dimensión, complejidad y prestigio no igualados antes ni después. Sigue siendo un centro científico importante, pero también un lugar donde la población recibe la atención y el trato que merece.

El impulso que recibe la organización de la clase obrera tiene profundas implicaciones en el terreno de la organización del sector salud, a través de la creación de obras sociales destinadas a prestar atención a la población que le corresponde. Este proceso se realiza dentro del marco de una política nacional y bajo la conducción del Estado, ya que este participa en la dirección de las obras sociales de los sindicatos. Va a ser en una etapa posterior en que la liberación de esa tutela condicione su crecimiento anómalo y la transformación de su carácter.

La gratuidad de la enseñanza en todos los niveles, la promoción de la política educacional y el elevado estatus social que era característica 
tradicional del médico fueron en buena parte responsables de que la carrera de medicina se viera abarrotada por postulantes que provenían no solo de la oligarquía, sino también de los sectores medios.

En otros aspectos se desarrolla una labor de tal magnitud que se traduce en la erradicación de algunas de las endemias que afectaban tradicionalmente a nuestro país (paludismo), en la reducción considerable de algunas enfermedades sociales (tuberculosis), en el impulso a la medicina preventiva, todo lo cual da una base firme para lograr, en ese período, los mejores índices de salud que ha tenido el país.

A partir de 1955 comienza la etapa que conduce a la situación política sanitaria que actualmente soportamos. Esta situación sanitaria responde a una concepción política conscientemente llevada a cabo y que de ninguna manera responde a "medidas técnicas desafortunadas". No debe haber errores ni autoengaños en este sentido; no se trata de marchas y contramarchas, nada tienen que ver los distintos cambios de gobierno de un mismo régimen. Siendo coherente la ideología de los grupos dominantes, también lo es una de sus manifestaciones: la política de salud. Los intentos que surgen como contradicción dentro del mismo régimen son rápidamente derrotados; la ley de medicamentos que promueve Oñativia tiene corta vigencia y ningún impacto real.

El enmarcamiento político de la etapa está dado por un sistema oligárquico capitalista dependiente, donde el objetivo principal es la multiplicación de las ganancias del grupo privilegiado. Surge entonces una posición clara con respecto a la salud: la salud como fuente de recursos económicos, o lo que es igual, la salud como negocio. En total coincidencia con esta postulación, el Estado orienta una deliberada política de destrucción del dominio y el manejo que tenía el nivel central de la administración sobre el sistema de salud: el Ministerio pasa a ser Secretaría y luego Subsecretaría con la consiguiente pérdida de control sobre el personal y el gasto.

De nuevo se repiten los esquemas de distintos tipos de salud según las clases a que va dirigido y según las áreas productivas. Habrá salud para los que poseen capital, es una salud cara y lujosa para la oligarquía. Habrá una salud más barata, impersonal, represora incluso, para los que producen la riqueza, los trabajadores, impulsada por la conveniencia de devolverlos rápidamente al proceso productivo. $Y$ finalmente un tercer tipo de salud de la cual sí conviene que el Estado se haga cargo, una salud que no es negocio: la del niño, del viejo y del crónico. Para los que no tienen dinero, para las poblaciones marginales del sistema productivo industrial, para el campo, para el "villero" y el desocupado habrá y hay enfermedad. Esto se agrava porque los presupuestos de los hospitales públicos se congelan o se reducen, teniendo muchos de estos que mal financiarse con el aporte de la población, que se hace ilegalmente obligatorio a través del mecanismo de las "cooperadoras". Se constituye así la ecuación de la desigualdad:

riqueza $=$ opresores $=$ salud

pobreza $=$ oprimidos $=$ enfermedad

Esta situación no nace sola. Nace después del arribo al poder de la "inteligencia" médica nativa y gorila, y trae "expertos" contratados por los grandes centros de poder económico que, en el informe que realizan, dejan traslucir sus dos postulados políticos fundamentales: 1) la salud es cara y alguien tiene que pagar por ella; 2) pero que no sea ni el Estado ni la oligarquía. Esto se traduce a nivel técnico en el programa de descentralización hospitalaria, y en el concepto de que el Estado debe auxiliar subsidiariamente a su mantenimiento.

A partir de entonces se comienza con el arancelamiento de los hospitales.

Esta es la base para descargar sobre la población el peso de atender su salud y para que los empresarios de la medicina hagan su negocio. El mismo informe de los expertos aconseja la descentralización de los programas de saneamiento, que pasan a depender del manejo local, lo cual en casos como paludismo, Chagas, fiebre amariIla, etc., significa un serio retroceso. Se desmantela el Instituto Malbrán reduciéndolo a una situación precaria, lo mismo ocurre con el Instituto de Farmacología, lo cual deja el campo libre a instituciones privadas.

A través de estas acciones se concreta nuestra dependencia sanitaria. El informe de estos "técnicos contratados" es la doctrina y la punta de lanza del imperialismo que encuentra en el 
cipayaje vernáculo sus agentes de realización que acatan obedientemente las sugerencias recibidas, una serie de gobiernos proimperialistas aportan la legislación necesaria para consolidar la situación.

La política que orienta la historia descripta tiene su correspondencia en la enseñanza de la medicina. Esa correspondencia no es total y sufre desajustes durante algunos períodos, como consecuencia de dos cosas: por una parte la desconexión total de los centros de decisión que tienen que ver con las acciones de salud y con la formación de recursos humanos para las mismas. No existieron mecanismos de coordinación que coordinaran las decisiones para actuar y las necesidades de formar personal para ello. Por otra parte, el entronizamiento de un grupo social, homogéneo en su proyecto social, aunque heterogéneo en su identificación política. El resultado fue una insuficiente flexibilidad para adecuar la enseñanza a las cambiantes condiciones del proceso histórico.

Graves contradicciones internas afectan hoy las posibilidades de que se pueda poner en marcha la Facultad hacia objetivos que adecuen su quehacer a lo señalado por los compañeros Cámpora y Liotta.

Ya hemos abierto la Facultad y la Universidad a todos quienes quieran estudiar en ella. Esto, que es la solución de un problema es a su vez la creación de otro porque significa estirar al máximo la capacidad de atender a la masa estudiantil que presuponemos acudirá a las aulas.

Pero el problema del ingreso no puede ser visto como un caso aislado, ni como una pura reivindicación política de los estudiantes, ni como una consigna de lucha para saber quiénes son amigos y quiénes enemigos. El problema del ingreso es solo otra de las manifestaciones de una situación que debe ser contemplada globalmente, para ubicarlo dentro de una situación y un proceso históricamente determinado, y para ir proponiendo soluciones permanentes a su cíclica reiteración como problema.

Por ello, debemos seguir al estudiante una vez traspuestas las puertas de entrada a esta casa, para saber qué ocurre a partir de allí. Una primera percepción que nos preocupa es la magnitud de los que se quedan en el camino. Aun en condiciones de ingreso restringido el problema del egreso asume características de suma gravedad. ¿Qué implicaciones tiene para esto el ingreso irrestricto?
¿Cómo se pueden solucionar? ¿En qué plazo? Hay una sola respuesta inaceptable por lo que desde ya queda rechazada: es el "no se puede".

Pero hay más. Es obvio que esta Facultad, y en especial en lo que corresponde a Medicina, no enseña solamente el arte de curar. Esta Facultad, además de enseñar, imparte formación profesional y social, en el marco de una política y un proyecto social global. Ese marco es el proyecto liberal que, con algunas vicisitudes, domina nuestra Universidad desde sus comienzos. La expresión de esto, en cuanto a la formación de los médicos, es el profesional que ve la salud como un mercado donde él forma parte de la oferta y el enfermo es un vehículo de demanda. Esta imagen es fuertemente reforzada por lo que muchos países que se dicen desarrollados nos intentan vender como la sabiduría suprema en el terreno de la salud.

No solo el enfoque profesional es el que acabamos de señalar. Este se liga, necesariamente, a un estatus social pretendido que hace que, poco a poco, el estudiante que ingresa a Medicina llevado por una pasión de servicio y amor al pueblo, termine con una visión oligárquica y deshumanizada que realimenta el círculo de la dominación y la dependencia.

- ¿Qué enseñanza estamos impartiendo a nuestros compañeros estudiantes?

- ¿Qué capacitación están adquiriendo los compañeros docentes?

- ¿Qué participación tienen en las decisiones los compañeros trabajadores?

- ¿Qué estamos haciendo por la salud del pueblo?

La etapa de Reconstrucción Nacional en que estamos empeñados requiere la revisión de los contenidos de la enseñanza y la investigación que se realiza en las Universidades, para nosotros en esta Facultad de Medicina, con el propósito de ponerlos en condiciones de servir al pueblo, que es su única justificación.

Docencia e investigación, tareas básicas de una Facultad que por lo tanto tienen una indiscutible jerarquía en su quehacer. Ambas pueden ser expresión de una lucha que ha sido definida por el General Perón como la gran causa nacional: dependencia o liberación.

Ya lo hemos definido en esta charla. El adiestramiento dependiente es aquel que parte 
de nuestra dependencia cultural para asumir como proyecto propio el de una medicina liberal, que ya no es aceptable ni siquiera para los defensores lúcidos de los países capitalistas. Como ejemplo de esta situación destaquemos un hecho que no es, en apariencia, discutible. La clínica se enseña en el Hospital Universitario. Pero el sanitarista sabe que de cada mil enfermos que piden auxilio médico, uno llega al Hospital Universitario porque la rareza o dificultad de su caso requiere ese nivel de complejidad.

En ese paciente se enseña medicina y en ese ámbito. Los restantes 999 quedan fuera de lo que la Facultad considera conveniente enseñar. $Y$ las condiciones en que se produce la enfermedad, el medio en que se desarrolla la situación epidemiológica, sea el taller, la fábrica, la villa, el barrio o el alucinante mundo del consumismo y la alienación, no entran en el cuadro que se ofrece a los ojos del educando. Si no ha perdido por completo su sensibilidad social, lo aprenderá por su cuenta, de lo contrario, será para siempre un hombre a medias, impedido de desarrollar al máximo sus capacidades en beneficio del pueblo al que se debe.

Ya se sabe de dónde viene esa concepción elitista y mercantilista de la medicina y la salud. Viene del mismo país que inventa permanentemente teorías y conceptos para justificar su ideología oscura, tantas veces puesta en descubierto.

Demanda y oferta, interpase médico paciente, son términos de una jerga pretendidamente científica que se utiliza como instrumento de penetración cultural. Ante ello debemos ser extremadamente críticos y pensar con conciencia nacional y popular acerca de lo que tenemos que enseñar y cómo, y de lo que necesitamos aprender. Pensar con conciencia nacional solo podemos hacerlo si miramos hacia nuestro país con sus problemas concretos tal como los hemos señalado en párrafos anteriores, en lugar de mirar hacia el extranjero para saber qué es lo moderno, lo que nos permite "estar al día" con una ciencia castrada o traidora. Pensar con conciencia popular es abrir nuestros sentidos a la vida que pasa todos los días por la calle, que no entra a los laboratorios o a las aulas pero espera o lucha desarrollando un proceso histórico del que no podemos estar ausentes si queremos cumplir con nuestro deber, el contacto que nos permita percibir los contenidos de esa vida histórica podemos iniciarlo en el debate amplio entre quienes estamos aquí.

Los que más sufren las agresiones del medio físico o social son quienes con más fuerza de convicción pueden contar lo que ocurre y lo que quiere el pueblo. Tal vez, y digo solo tal vez, los compañeros trabajadores manuales no expresen sus sentimientos con palabras tan bonitas como las nuestras, pero no quepa ninguna duda que serán mucho más justas, porque vienen de una experiencia directa que nada puede reemplazar.

$Y$ nosotros, que junto con todos los compañeros trabajadores, formamos parte de un gobierno nacional y popular, estamos obligados a hacer lo que el pueblo quiera.

Compañeros, no caerán las murallas de Jericó con mi llamado, pero me conformo por ahora con derribar simbólicamente las paredes que transforman el Decanato de la Facultad de Medicina en una fortaleza medieval. Desearía que el resto de los compañeros que trabajan en la casa hagan lo mismo si están rodeados por muros que los aíslan.

Ello signifique tal vez más trabajo para todos, más tiempo dedicado a tareas que pueden no ser del agrado de todos, pero que son la base única de la reconstrucción, que es un imperativo. ¿Y qué es el tiempo nuestro destinado a esta tarea, al lado del tiempo que ya no pueden disponer los queridos compañeros combatientes que cayeron en acciones o en la represión del régimen o de los traidores?

La investigación es otro pilar fundamental del quehacer de esta casa. ¿Qué más decir que ya no se haya dicho? Creo que no vale la pena reabrir desde aquí un viejo debate que para mí está definitivamente agotado, porque en su forma de antinomias representa un falso problema. Investigación pura versus investigación aplicada. Ciencia nacional versus ciencia supranacional. Investigación versus enseñanza. Ciencia comprometida versus ciencia verdadera. Verdad versus política. ¿Hasta cuándo esta discusión estéril y engañosa?, que se estimula solo para desviarnos del verdadero debate que es: o nosotros damos a la investigación el contenido que debe tener, o la política científica la decide el imperialismo y sus aliados internos, conscientes o inconscientes. De nuevo, y no gratuitamente, el 
dilema es el que señalara con genial lucidez nuestro líder indiscutido, el Teniente General Perón, liberación o dependencia.

Es indudable que así como intentamos poner la labor de esta casa al servicio de los planes de salud, la tarea de investigación tendrá que estar en relación con los mismos y con los lineamientos que desde las esferas pertinentes del gobierno se den para una política científica nacional y popular, de contenidos propios, de métodos originales, de relación estrecha con lo que el trabajador de salud debe saber.

Existe una infraestructura física y humana importante para la investigación pero quiero destacar que es necesario incentivar la creatividad de todos en este terreno. La investigación debe salir de los laboratorios. Debemos recordar que la medicina es una ciencia biológica con proyecciones sociales y, como tal, muchos aspectos que pueden ayudar a solucionar sus problemas son los organizativos. Esto, que es tecnología social, puede "investigarse" sin equipos complicados, en base a la formidable fuerza de trabajo que representan los estudiantes.

¿Sabemos, por ejemplo, qué consecuencias tiene sobre un grupo de población villera el abastecimiento de agua potable para su situación de salud? No, no lo sabemos, y ese es un dato vital para estimar los resultados de las acciones que el gobierno popular va a desarrollar.

Pero también dentro de los laboratorios la tarea debe pasar por lo nacional y popular. Esto puede despertar la sonrisa irónica de los que adoran a la ciencia como a ese dios que por estar más allá de los hombres es intocado por sus manos sucias y sudorosas. Intocado por manos humanas, como me señalaba un amigo querido años atrás: "untouched by human hands!", me decía con su tono salteño de poeta, como si hubiera algo noble y digno en este mundo que no sea tocado por las manos de los hombres.

A este respecto solo quiero señalar que entiendo la pasión individualista que puede sentir un investigador por el método que utiliza, pero es imprescindible destacar que lo popular no tiene por qué estar en contra de lo riguroso.

Lo nacional, en cambio, exige que los contenidos de la investigación, los métodos que se utilizan, los fondos financieros, y el destino que se dé a los resultados, sean observados muy detallada y críticamente por los propios investigadores, por sus ayudantes y colaboradores, por los trabajadores y los estudiantes, y por el pueblo organizado, único fiscal inapelable.

Abierta la Facultad hacia la calle, sus programas de enseñanza y de investigación serán, simultáneamente, programas de extensión universitaria, porque en última instancia el deber de una Universidad, en esta etapa de liberación, es transferir el conocimiento al pueblo.

En resumen, los lineamientos más generales que van a guiar la acción de esta intervención van a estar al servicio de la lucha por la liberación, en los marcos fijados por el gobierno nacional y popular.

La solidaridad como expresión de la Argentina que queremos, la participación como método de trabajo, y la desmitificación del rol de la ciencia como verdad absoluta, serán los principios ordenadores de nuestro trabajo.

Centraría en este momento mi preocupación por el ingreso, la progresividad de la carrera de ciencias de la salud para que se fueran formando capacidades de creciente jerarquía, la integración del estudio con el trabajo y la investigación para los estudiantes, la descentralización de la enseñanza y la puesta de nuestro quehacer al servicio del pueblo a través de la coordinación con los planes de salud del gobierno nacional.

Compañeros docentes y no docentes, compañeros trabajadores, compañeros estudiantes, desde este momento quedan convocados a realizar desde cada cátedra o cada centro de trabajo, la discusión sobre estos problemas que hemos planteado, para lo cual pido que se formen mesas de trabajo o comisiones con la participación de todos, para empezar a instrumentar el gobierno de esta casa en la forma más democrática posible, y para que surjan de ustedes las respuestas a los interrogantes que nos angustian. La intervención, por su parte, formará comisiones a nivel del Decanato, para recibir las propuestas que se elaboren en los distintos centros de movilización. Esto debe tener concreción inmediata porque el compañero Ministro de Educación ha solicitado al compañero Interventor en nuestra Universidad sus puntos de vista sobre la nueva Ley Universitaria, en consulta con todos los que participan en el quehacer de nuestras casas de estudios. 
Esto debe entregarse antes del 15 de agosto próximo, pero ello no significa que la discusión se termina en esta fecha. Lo que inauguramos hoy es algo permanente. Nunca más se cerrarán las puertas del Decanato. Nunca más a espaldas del pueblo sino de frente, con el pueblo, golpeando con mano firme y con el corazón joven, hasta que se abran, o hasta que las derribemos, las puertas de la liberación.

Compañeros, a trabajar.

\section{FORMA DE CITAR}

Testa M. La capacitación, la enseñanza y la investigación para una política de reconstrucción nacional en el área de la salud. Salud Colectiva. 2012;8(3):323-335. 